\title{
The absorption and secretion of calcium in the gastrointestinal tract of germ-free and conventional chicks
}

\author{
By MAUREEN F. PALMER* AND B. A. ROLLS \\ National Institute for Research in Dairying, Shinfield, Reading, RG2 9AT
}

(Received 12 November 1979 - Accepted 2 July 1981)

\begin{abstract}
1. The uptake, transport and secretion of calcium into the gastrointestinal tract of germ-free (GF) and conventional (CV) chicks was determined by a variety of in vivo and in vitro techniques using ${ }^{45} \mathrm{Ca}$ as a marker following a standard fast-feed regimen.

2. Following an oral dose of $\mathrm{Ca}$ in conscious chicks, the transit time of digesta in the GF birds was appreciably faster than in the CV controls.

3. Although the proportion of the Ca dose absorbed was similar in both groups of chicks, the accumulation of $\mathrm{Ca}$ in the intestinal wall was :nuch greater in $\mathrm{CV}$ birds. Distribution of the labelled $\mathrm{Ca}$ in plasma and bone was similar in both groups.

4. Following intravenous $\mathrm{Ca}$ injection in conscious chicks the Ca secretion into the intestinal lumen was similar in both groups, but the amount appearing in the gut wall was appreciably greater in CV chicks.

5. There were regional differences in the ability of the gut to absorb $\mathrm{Ca}$. There was a tendency for $\mathrm{Ca}$ uptake to be greater in the GF chicks but only in the proximal ileum did this approach significance.

6. When the $\mathrm{Ca}$ was confined to an intestinal loop the uptake/g tissue was similar in the proximal ileum of both groups but significantly greiter in the distal ileum of the GF group. Uptake/10 mm gut was similar in both groups at both the proximal and the distal site.

7. It is suggested that the absence of a microbial load does not affect the ability of the enterocyte to absorb $\mathrm{Ca}$ but the subsequent removal of the absorbed load from the intestinal wall is appreciably slower in the CV group.
\end{abstract}

The growth rate of chicks maintained in a germ-free (GF) environment is faster than that of their conventional ( $\mathrm{C} V$ ) counterparts (Coates et al. 1963) and since there is close correlation between growth rate and calcium uptake (Adams \& Norman, 1970) the requirement for this mineral might be expected to be greater in the GF chick. Absorption of $\mathrm{Ca}$ and magnesium, as estimated by balance studies, has been shown to be greater in the GF rat compared to CV controls (Reddy et al. 1969) while uptake of Ca and its incorporation into bone was found to be greater in GF chicks when compared to CV birds (Edwards \& Boyd, 1963). In addition to the increased growth rate in the GF environment, the absence of a microflora causes marked thinning of the gut, due to a reduction in the lamina propria (Gordon \&: Bruckner-Kardoss, 1961), and a reduction in cell turnover and migration rate (Rolls et al. 1978). Such differences in morphology might be expected to increase the absorptive capacity of the GF gut.

The present study was undertaken to assess the effects of the microflora on the uptake of $\mathrm{Ca}$ by the enterocytes, the site of uptake and the fate of an oral and a parenteral $\mathrm{Ca}$ load.

A preliminary report of part of this work has already been published (Palmer \& Rolls, 1978).

\section{MATERIALS AND METHODS}

Chicks. Rhode Island Red $\times$ Light Sussex chicks were used. Eggs from a specified pathogen free flock maintained at the Institute were incubated for $18 \mathrm{~d}$ in a commercial incubator and then decontaminated with peracetic acid (Harrison, 1969). Those destined for the

- Present address: Departmert of Physiology, Queen Elizabeth College, University of London, Campden Hill Road, London W8 7AH. 
production of GF chicks were transferred to Gustafsson stainless-steel isolators to hatch, while the rest were returned to the incubator and the chicks subsequently hatched were reared as CV controls. After hatching, the GF chicks were divided into groups of four and housed in stainless-steel cages with mesh floors within the isolators while the CV controls were housed in similar cages in a room where the environmental conditions could be matched to those of the isolators. As far as possible males and females were distributed evenly among the groups. Sterility checks on the chicks within the isolators were made at intervals (Fuller, 1968).

Diets. The chicks were fed a practical mash (SCM) the composition of which was $(\mathrm{g} / \mathrm{kg})$ maize meal 350 , wheat meal 300 , middlings 85 , white fish meal 100 , dried skim milk 75 , dried grass meal 30, dried brewer's yeast 30 , limestone flour 15 , sodium chloride 4.697 , hydrated manganese sulphate 0.3 ; maize oil 10 and potassium iodide $3 \mathrm{mg} / \mathrm{kg}$. Cholecalciferol was dissolved in the maize oil to provide $16 \mu \mathrm{g} / \mathrm{kg}$ diet. 'A500 Rovimix' (Roche Products Welwyn Garden City, Herts.) was added to give $2 \mathrm{mg}$ retinol $/ \mathrm{kg}$. The diet was packed in plastic bags which were evacuated and sterilized by $5 \mathrm{Mrad} \gamma$ radiation.

Reagents. ${ }^{45} \mathrm{CaCl}_{2}$ was obtained from the Radiochemical Centre, Amersham, Bucks. All other reagents used were of Analar grade and were obtained from British Drug Houses, Poole, Dorset.

\section{Plan of experiments}

All investigations were made on comparable groups of GF and CV chicks from the same batch of eggs.

Since transit times of digesta are known to increase following a period of fasting, a pre-experimental feeding regimen was adopted for all experiments. The chicks were fasted for $16 \mathrm{~h}$ and then allowed access to food for exactly $1 \mathrm{~h}$ before the experiment began.

Expt 1 . This was designed to compare transit time and uptake of $\mathrm{Ca}$ at various sites within the gastrointestinal tract and accumulation of $\mathrm{Ca}$ into bone at graded intervals up to $1 \mathrm{~h}$ in conscious chicks. Each chick was intubated into the proventriculus and a dose of $0.1 \mu \mathrm{Ci}$ ${ }^{45} \mathrm{Ca}$ in $40 \mathrm{~mm}-\mathrm{CaCl}_{2}$ was administered in a total volume of $2 \mathrm{ml}$, giving a total $\mathrm{Ca}$ load of $3.5 \mathrm{mg}$. Two birds from each group were killed by intravenous injection of sodium pentobarbitone at intervals of from $5 \mathrm{~min}$ to $1 \mathrm{~h}$ after dosing. The gastrointestinal tract was rapidly tied off to isolate sections as follows: (1) proventriculus, (2) duodenum, (3) proximal ileum (pancreatic duct to yolk-sac stump), (4) distal ileum 1 (yolk-sac stump to limit of caeca), (5) distal ileum 2 (to the ileocaecal junction). The gut was removed and each segment was washed through with isotonic saline $(8.5 \mathrm{~g} \mathrm{NaCl} / \mathrm{l})$ and the washings collected for counting. Each segment was opened lengthways, rinsed in saline and blotted dry. The right tibiotarsus was removed and scraped clean of muscle. Washings, gut tissue and bone were ashed and the ash dissolved in $2.0 \mathrm{M}$-hydrochloric acid and the ${ }^{45} \mathrm{Ca}$ content measured by liquid-scintillation counting using a Packard Tri-carb liquid-scintillation spectrophotometer (Model 3003) using the internal standard technique.

Expt 2. In an attempt to assess the amount of $\mathrm{Ca}$ secreted into the gut, the procedure adopted in Expt 1 was repeated replacing the oral dose of $\mathrm{Ca}$ with an intravenous injection of $0.1 \mu \mathrm{Ci}(3.5 \mathrm{mg} \mathrm{Ca})$ in a total injection volume of $0.5 \mathrm{ml}$. Gut washings and tissues were treated as described previously.

Expt 3. Since differences in transit time may mask differences in absorptive capacity at the various sites, Expt 3 was designed to assess in vitro the potential of the enterocytes for $\mathrm{Ca}$ uptake. The gut was removed from anaesthetized chicks and divided as in Expt 1. Each segment was everted and rings, $3 \mathrm{~mm}$ in width, were cut from the mid part of each segment. The rings were incubated in a modified oxygenated Krebs saline (Spencer et al 1978) containing $0.1 \mu \mathrm{Ci}^{45} \mathrm{Ca} / 20 \mathrm{ml}$ saline. Rings were removed at intervals of from 1 to $15 \mathrm{~min}$ 
from the incubation medium, rinsed briefly, blotted dry, weighed and then dissolved in $5 \mathrm{M}-\mathrm{HCl}$ for $24 \mathrm{~h}$ before ${ }^{4: \mathrm{Ca}}$ was determined.

Expt 4. In vivo uptake of $\mathrm{Ca}$ from intestinal loops was studied. Chicks were anaesthetized with sodium phenobarbitone $(100 \mathrm{~g} / \mathrm{l})$ at a dose of $20 \mathrm{mg} / \mathrm{kg}$ body-weight. An incision was made in the abdominal wall to expose the intestine and the position of the yolk-sac stump was located. Loops were rnade of either proximal or distal ileum. The loops were washed through with oxygenated Krebs saline before being filled with saline containing $20 \mu \mathrm{Ci}$ ${ }^{45} \mathrm{Ca} / \mathrm{l}$. The loops were replaced in the abdominal cavity and left in situ for periods of from 5 to $60 \mathrm{~min}$. The loops were then emptied, washed through with saline and the saline together with washings was dried and ashed as described previously. The loops were weighed, the length meast red and the ${ }^{45} \mathrm{Ca}$ content determined as previously.

Statistical analysis. The data from Expts 3 and 4 were subjected to analysis of variance. In Expt 3 the data for each site were treated separately and each of the sixteen chicks was considered to be an experimental unit with repeated observations being made at seven times. The analysis followed the suggestion of Rowell \& Walters (1976).

In Expt 4 each chick gave only one result so the data were regarded as independent. However, reliability of the data increased as uptake increased so the results were transformed into logarithms to give homogeneous variances. The logarithms were analysed by analysis of variance and time and en vironment effcts were assessed using the variation between chicks within times and environments.

\section{RESULTS}

Expt I (Fig. 1) shows the liminal ${ }^{45} \mathrm{Ca}$ content and the accumulation of ${ }^{45} \mathrm{Ca}$ within tissues for each of the segments o: the gastrointestinal tract following an oral dose of labelled $\mathrm{Ca}$. The rate of appearance in the various segments indicated that the transit time was appreciably shorter in the GF compared with the CV birds. The total uptake of Ca from all segments is shown in Fig. 2. This was calculated by addition of the Ca remaining in the lumen of all sections of the gut minus the $\mathrm{Ca}$ secretion into the lumen determined after intravenous dosing in Expt 2. Uptake was very rapid and within $5 \mathrm{~min}$ of the dose being given approximately four-jifths had disappeared from the lumen. There was no difference between the GF and CV birds in either the rate of uptake or the amount of the dose absorbed. At the longer time intervals less $\mathrm{Ca}$ appeared to be absorbed by the $\mathrm{CV}$ birds.

Although the pattern of accumulation of the labelled $\mathrm{Ca}$ in the gut tissues was similar in both groups, both exhib ting a peak at $5 \mathrm{~min}$ and a rather smaller peak after $30 \mathrm{~min}$ (Fig. 3), the magnitude of the accumulation was different in the two groups. The CV birds accumulated twice as much $\mathrm{Ca}$ in the gut wall at the two peaks compared with the GF birds although the amount left $50 \mathrm{~min}$ after dosing was similar. The deposition of the labelled $\mathrm{Ca}$ in bone was similar in both groups.

Following an intravenous dose of $\mathrm{Ca}$ (Expt 2) the pattern and amount of secretion into the gut lumen was similar in both groups (Fig. 4). Analysis of the gut tissue showed that the amount of the dose appearing in the CV gut was approximately twice that of the GF gut within the first $5 \mathrm{~min}$ after the dose was given but the amount held in the gut wall diminished gradually and by 60 min following dosing the $\mathrm{Ca}$ content of the CV gut was only a little greater than that of the GF chicks.

Table 1 shows the ${ }^{45} \mathrm{Ca}$ uptake by isolated rings of intestine (Expt 3) and Fig. 5 gives an example of the data for the distal ileum with the fitted line. Considering the results for each site and time separately, only duodenum at $4 \mathrm{~min}$, proximal ileum at $15 \mathrm{~min}$ and distal ileum at $1 \mathrm{~min}$ showed significant differences between germ-free and conventional chicks $(P<0.05, P<0.05$ and $P<0.01$ respectively). It is noticeable however, that values for germ-free chicks were generally slightly greater than values for conventional birds, but such 
(a)

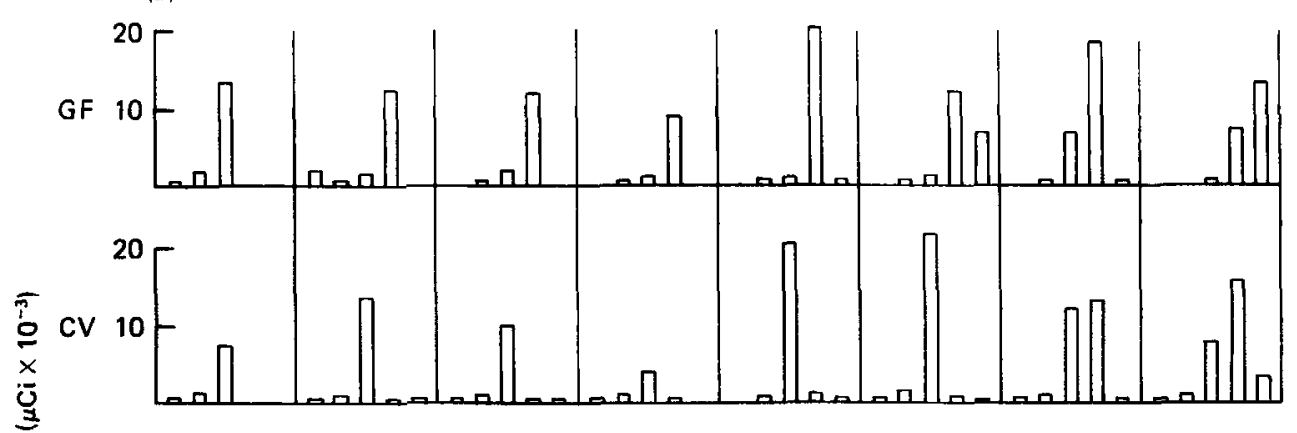

(b)

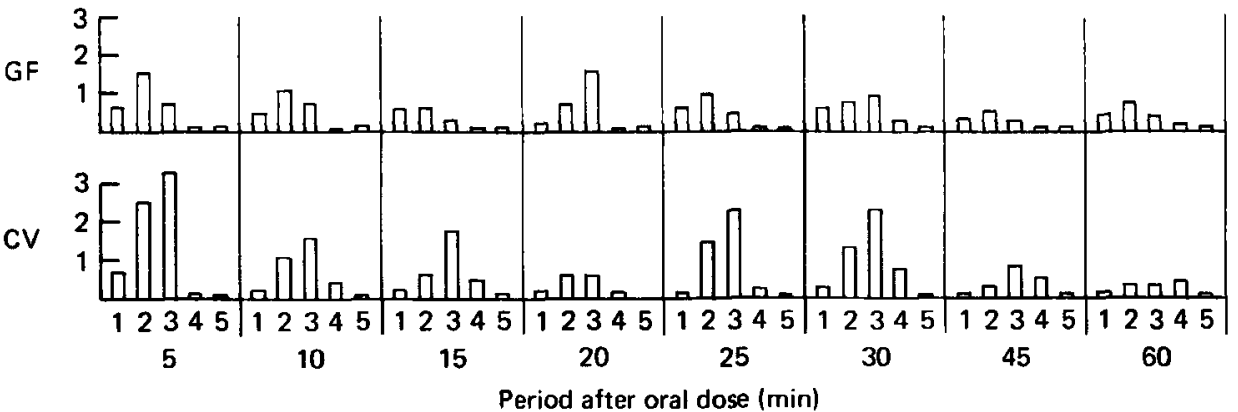

Fig. 1. Expt 1. Total ${ }^{45}$ calcium $\left(\mu \mathrm{Ci} \times 10^{-3}\right)$ found in $(a)$ luminal contents and $(b)$ intestinal tissues of the following sections of the gut of groups of two germ-free (GF) and conventional (CV) chicks at intervals after oral administrations. (1) Proventriculus, (2) duodenum, (3) proximal ileum, (4) distal ileum 1 and (5) distal ileum 2.

consistency might be expected since the same sixteen birds were involved in each comparison. Analysis of variance as outlined in Materials and Methods, showed no significant differences between environments. In contrast, highly significant linear $(P<0.001)$ and quadratic $(P<0.01)$ effects were evident at the first four sites, at distal ileum 2 only the linear effect was significant $(P<0.001)$. There was also a strong suggestion of an interaction between the linear effect and environment for the proximal ileum $(P=0.051)$ indicative of more rapid uptake by the germ-free isolated rings. There were some regional differences in uptake, the sites of greatest uptake being the proventriculus and the distal ileum 2.

Table 2 gives the ${ }^{45} \mathrm{Ca}$ uptake in tied loops of proximal and distal intestine (Expt 4). These results indicate that initially in the proximal ileum there was a marked uptake but little subsequent increase with time, whilst in the distal ileum after the initial rapid uptake there was a substantial increase between 30 and 60 minutes $(P<0.01)$. When uptake/g tissue was considered there was no difference between the groups in uptake of $\mathrm{Ca}$ in the proximal ileum but in the distal ileum the uptake in the GF birds was always greater and the mean significantly so $(P<0.001)$. Uptake $/ 10 \mathrm{~mm}$ gut failed to reveal any difference in uptake either in the proximal or the distal ileum. The lengths of the segments used were very comparable in the two groups but as shown in Table 2 the weight/unit length was significantly less in the GF chicks. 


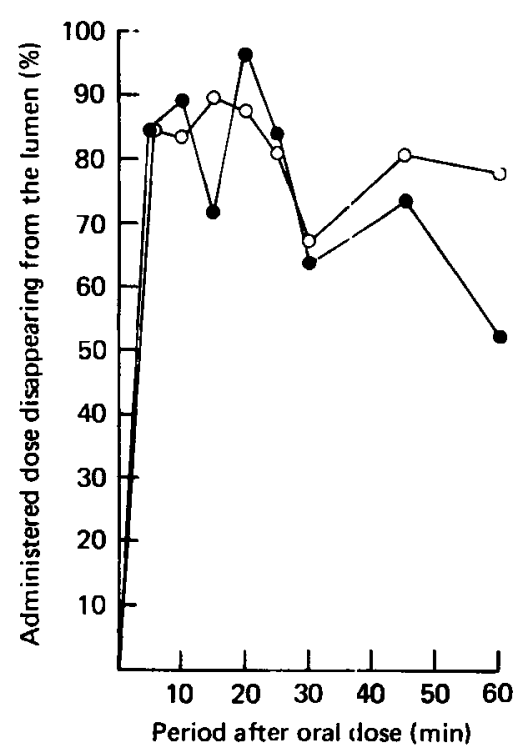

Fig. 2.

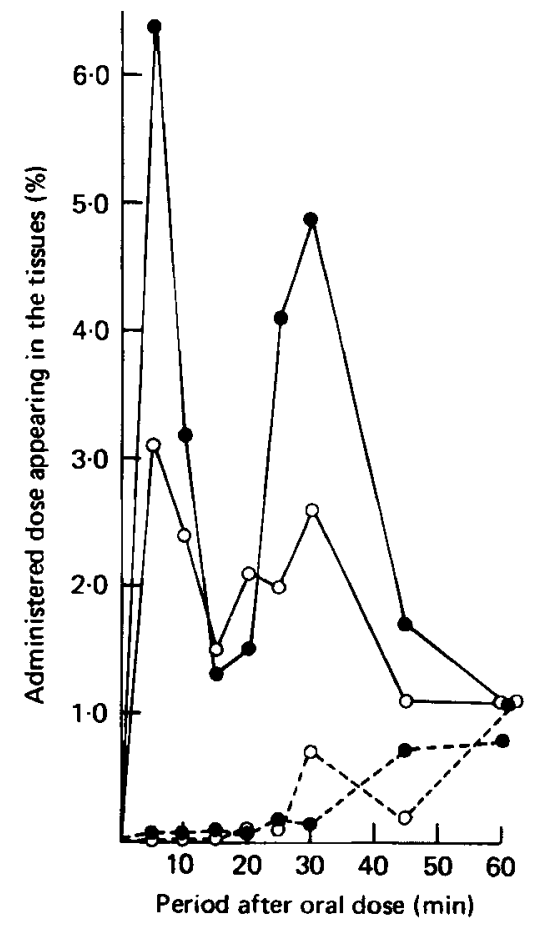

Fig. 3.

Fig. 2. Expt 1. Rate of disarpearance of an oral ${ }^{45} \mathrm{Ca}$ load expressed as a $\%$ of the total dose given in germ-free $(\mathrm{O}-\mathrm{O})$ and conventional $(\mathrm{O}-\mathrm{O})$ chicks.

Fig. 3. Expt 1. Rate of appestrance of ${ }^{45} \mathrm{Ca}$ in the gut wall (-) and bone (--) in germ-free $(\mathrm{O})$ and conventional $(\mathcal{O})$ chicks expressed as percentage of the oral dose given.

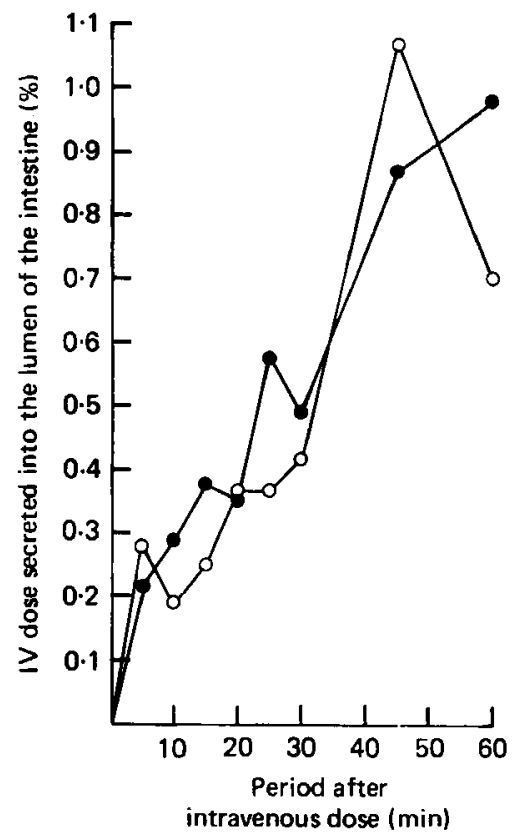

Fig. 4. Expt 2. Secretion of ${ }^{45}, \mathrm{Za}$ into the lumen of the gut following intravenous (IV) dosing in GF and CV chicks expressed as percentage total dose given. 


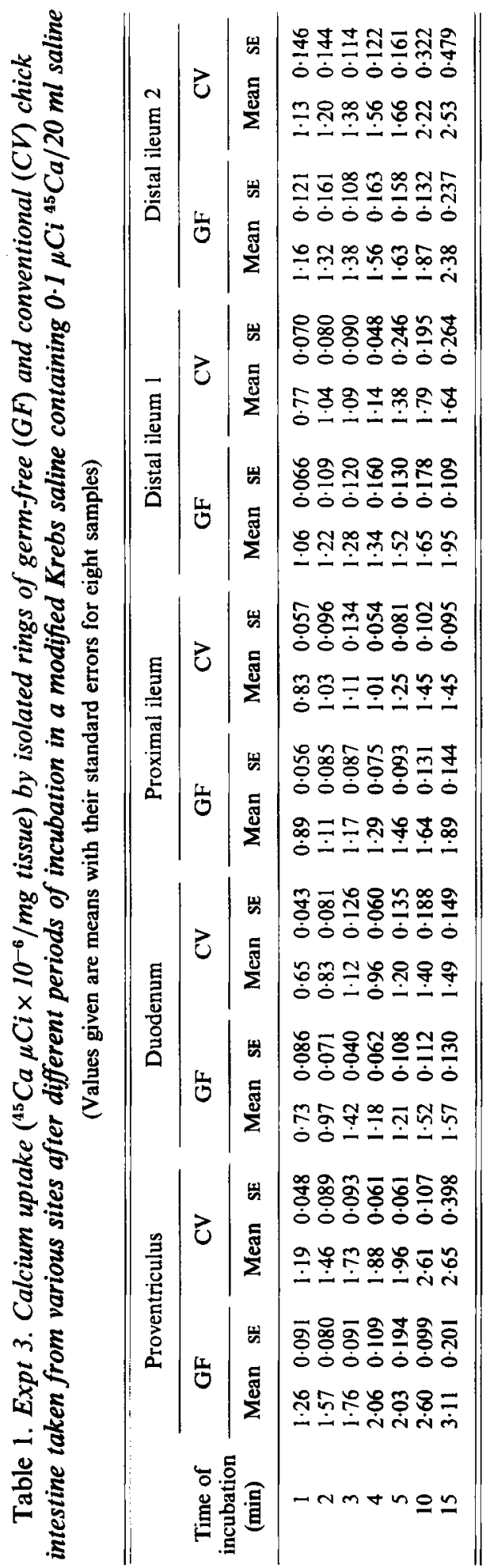




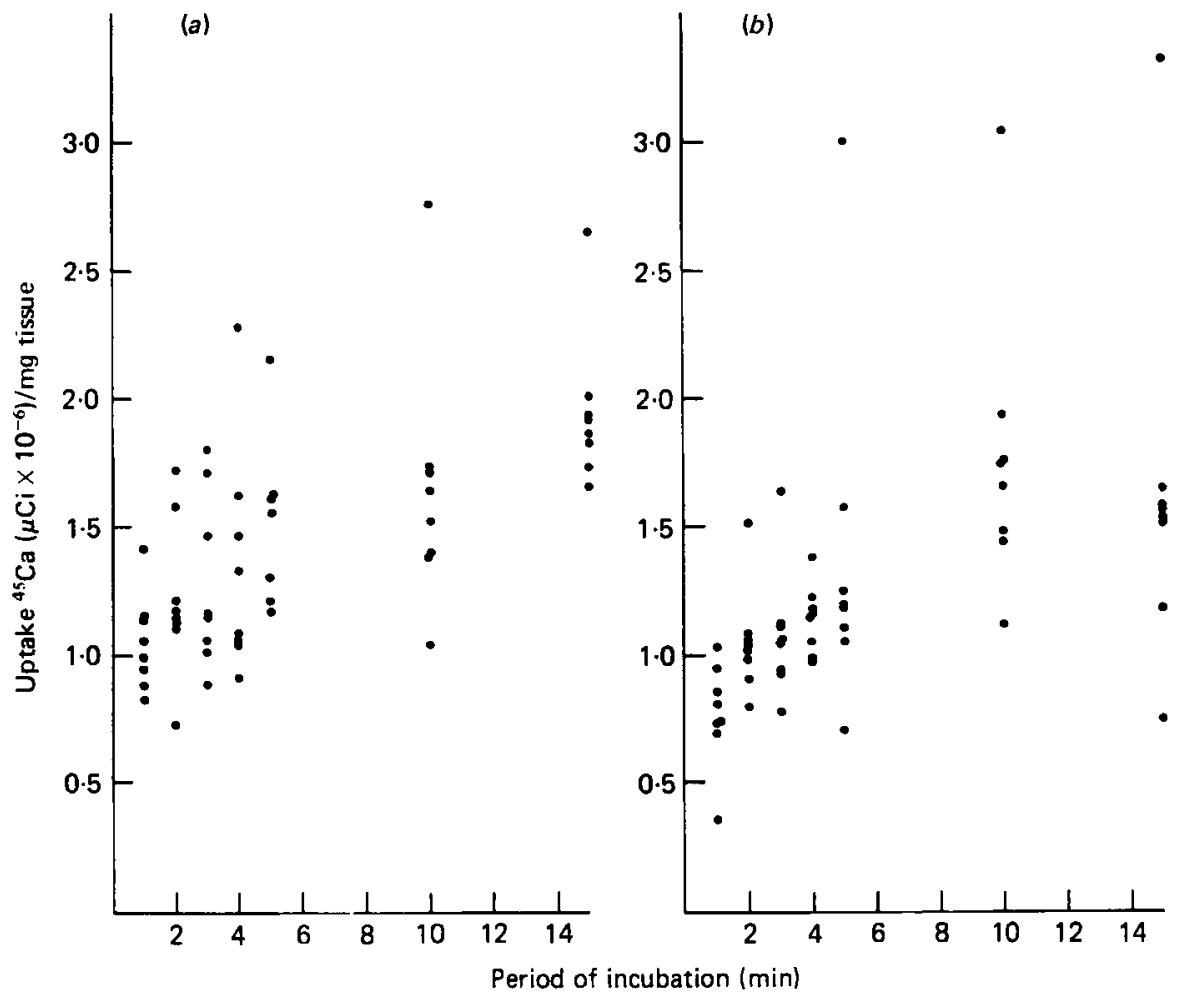

Fig. 5. Expt $3 .{ }^{45} \mathrm{Ca}$ uptake $\left(u \mathrm{Ci} \times 10^{-6}\right) / \mathrm{mg}$ wet weight tissue by rings of distal ileum 1 in $(a)$ germ-free and $(b)$ conventional chicks at intervals of incubation in modified $\mathrm{Krebs}$ saline containing $0 \cdot 1{ }^{45} \mathrm{Ca} / 20 \mathrm{ml}$ saline.

\section{DISCUSSION}

Comparing the $\mathrm{Ca}$ uptake by chicks in the GF and CV environments no difference between the groups was demonst:ated. The enterocyte uptake mechanism, although initially probably a passive process (Spencer et al. 1978), must occur very rapidly since within $5 \mathrm{~min}$ of a dose of labelled Ca being given either orally in conscious birds (Expt 1) or into loops of intestine in anaesthetized chicks (Expt 4), some four-fifths of the dose had been absorbed. When the time course of the uptake was studied in an in vitro preparation (Expt 3) the rapidity of the uptake prccess was confirmed and saturation, or near saturation of the uptake mechanism is apparent within 5-10 min incubation with the label. The amount of ${ }^{45} \mathrm{Ca}$ disappearing from the lumen at 45 and $60 \mathrm{~min}$ after dosing (Expt 1 ) was less than that at the earlier times which is probably a reflection of resecretion of unlabelled $\mathrm{Ca}$ into the lumen of the gut.

The accumulation of $\mathrm{Ca}$ within the intestinal wall exhibited a double peak, the maximum value occurring $5 \mathrm{~min}$ after dosing and a second smaller peak 30 min after dosing (Expt 1). The peak values in the git wall of the CV chicks were twice those of the GF chicks. This pattern of appearance of $\mathrm{Ca}$ in the gut wall could be explained by very rapid uptake of Ca by the enterocytes and slow removal of the absorbed dose into the blood stream to form the first peak, while the second peak might reflect the redistribution of $\mathrm{Ca}$ in the blood returning to the gut, since the peak occurring at $30 \mathrm{~min}$ was also seen following intravenous dosing (Expt 2). GF chicks have a thinner gut wall than their CV counterparts mainly due 


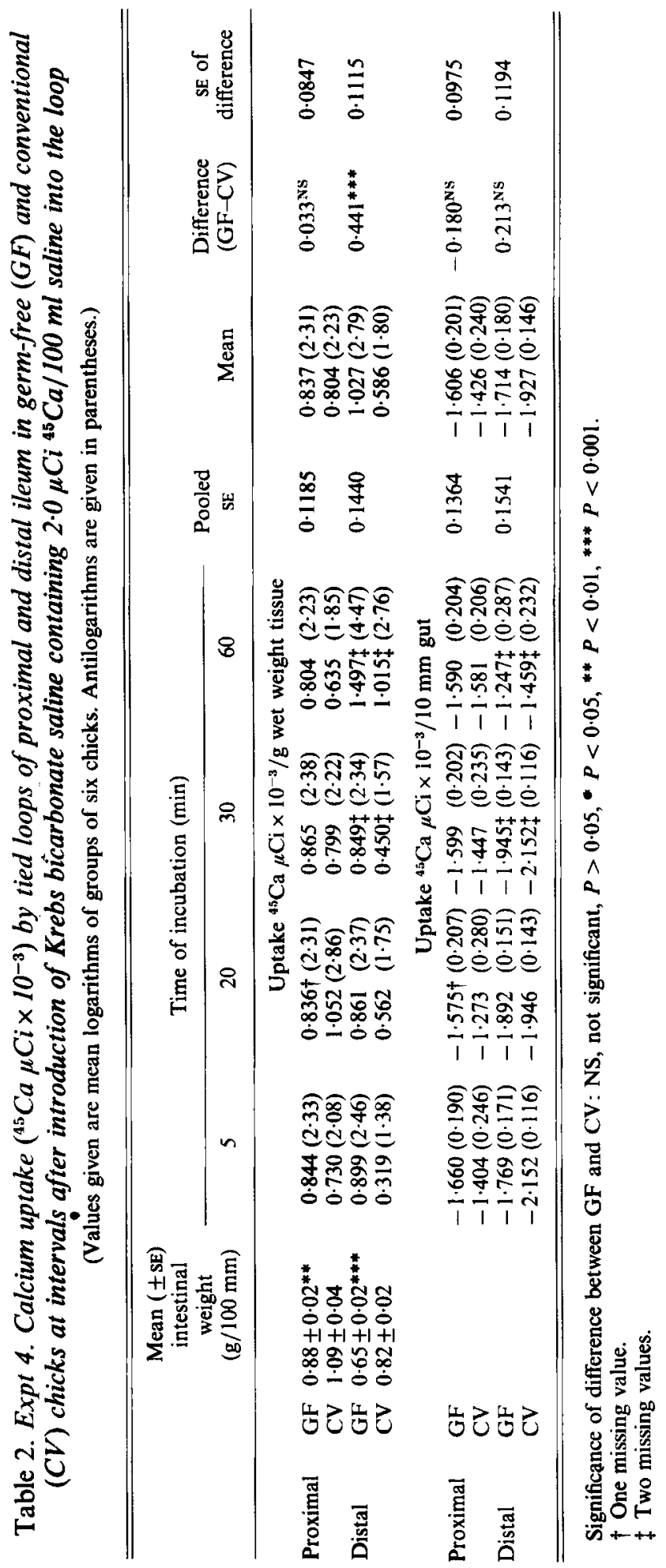


to a reduction in the lamina propria (Gordon \& Bruckner-Kardoss, 1961) thus the enterocyte-capillary distance would be smaller and a more rapid removal of absorbed nutrients from the gut wall might be expected to occur. Other factors which might explain the faster removal of $\mathrm{Ca}$ from the gut wall could be an increased rate of synthesis of calcium-binding protein (LaBP) or local alterations in blood flow.

Although the rate of disappearance of the labelled $\mathrm{Ca}$ from the gut lumen was similar in both groups, its transport away from the gut wall was more rapid in the GF chicks (Expt 1), but since the levels of $\mathrm{Ca}$ in the blood were similar in both groups it seems likely that there might have been a more rapid excretion of the dose in the GF group. Gustafsson \& Norman (1962) suggested that as GF rats frequently develop urinary calculi, indicating an increased excretion of $\mathrm{Ca}$, the whole $\mathrm{Ca}$ equilibrium is disturbed in the absence of the microflora. There has been some evidence to suggest that $\mathrm{Ca}$ deposition in bone is greater in the GF state (Edwards \&: Boyd, 1963) but these findings were not confirmed in the present study: the incorporation of the labelled $\mathrm{Ca}$ into bone over a period of $1 \mathrm{~h}$ being similar in both groups (GF $0.8 \times 10^{-3}, \mathrm{CV} 1.1 \times 10^{-3} \mu \mathrm{Ci}$ ).

There was no difference between the groups as to the amount of $\mathrm{Ca}$ appearing in the secretions of the gut in the conscious chicks and since most of this $\mathrm{Ca}$ is derived from the pancreatic secretions this would suggest that pancreatic function is similar in the two groups.

Measurement by Ford (1971) of transit times through the entire intestine failed to show any difference between the GF and CV chicks whereas we found a very striking difference in the transit of an oral dose of $\mathrm{Ca}$, the transit time in the GF group being appreciably shorter than in the CV controls. The lack of agreement between the two findings may result from the different experimental conditions. Loss of muscle tone has been reported in many species and seems to be characteristic of the GF state. This characteristic may account for the difference in intestinal transit time.

All parts of the gut apprear to have the ability to absorb $\mathrm{Ca}$ but the experiment using isolated rings of intestine (Expt 3 ) demonstrates that there are regional differences in uptake ability; the proventriculus and distal ileum having a greater uptake than the duodenum. There was a trend for uptake to be greater in the GF chicks compared with the CV controls and in the proximal ileum the interaction between the linear effect and the environment approached significance suggesting a greater uptake in the GF chicks.

Measurements of $\mathrm{Ca}$ up:ake by loops in anaesthetized chicks (Expt 4) showed that there was no difference in uptalie in the proximal ileum whether expressed in relation to unit weight or unit length but in the distal ileum uptake/g tissue was significantly greater in the GF chicks, while uptake expressed $/ 10 \mathrm{~mm}$ approached significance $0.1>P>0.05$. This is somewhat surprising since $\mathrm{Ca}$ uptake is more efficient at acid pH and Ford (1974) showed that the pH of the distal ileum was lower in CV birds. The thinning of the intestine is much more apparent at the distal region of the intestine and the difference in uptake probably reflects the reduced enterocyte-capillary distance rather than any real difference in the ability of the enterocyte to absoris $\mathrm{Ca}$.

Although the uptake of Ca was generally greater in the GF birds, and significantly greater in the distal ileum of the GF birds, there was no evidence that the overall Ca economy was affected. Deposition in bone and plasma $\mathrm{Ca}$ concentration were similar in both environments suggesting either that the extra absorption was quantitatively insignificant or that excretion was more rapid.

The authors wish to thank Dr Marie Coates for invaluable help and encouragement during this work, Dr D. Hewitt for advice on the statistical treatment, Mr J. Fordham for maintenance of the germ-free chicks, Dr D. Jayne-Williams for checking sterility of the germ-free isolators and Miss M. Tyler for technical assistance. 


\section{REFERENCES}

Adams, T. H. \& Norman, A. W. (1970). J. biol. Chem. 245, 4421.

Coates, M. E., Fuller, R., Harrison, G. F., Lev, M. \& Suffolk, S. F. (1963). Br. J. Nutr. 17, 141.

Edwards, H. M. \& Boyd, F. M. (1963). Poult. Sci. 42, 1030.

Ford, D. J. (1971). Some aspects of digestive physiology of germ-free and conventional chicks. $\mathrm{PhD}$ Thesis, University of Reading.

Ford, D. J. (1974). Br. Poult. Sc. 15, 131.

Fuller, R. (1968). In The Germ-Free Animal in Research, p. 37 [M. E. Coates, editor]. London: Academic Press.

Gordon, H. A. \& Bruckner-Kardoss, E. (1961). Acta anat. 44, 210.

Gustafsson, B. E. \& Norman, A. (1962). J. exp. Med. 116, 273.

Harrison, G. F. (1969). Lab. Anim. 3, 51.

Palmer, M. F. \& Rolls, B. A. (1978). Proc. Nutr. Soc. 37, 114A.

Reddy, B. S., Pleasants, J. R. \& Wostmann, B. S. (1969). J. Nutr. 99, 353.

Rolls, B. A., Turvey, A. \& Coates, M. E. (1978). Br. J. Nutr. 39, 91.

Rowell, J. F. \& Walters, D. E. (1976). J. agric. Sci., Camb. 87, 423.

Spencer, R., Charman, M., Wilson, P. W. \& Lawson, D. E. M. (1978). Biochem. J. 170, 93. 